\title{
Incidence and Risk Factors of Hypertensive Disorders of Pregnancy - 8 Provinces, China, 2014-2018
}

\author{
Wei Zhao'; Jiangli $\mathrm{Di}^{1, *}$; Aiqun Huang'; Qi Yang'; Huanqing $\mathrm{Hu}^{1}$
}

\section{Summary \\ What is already known about this topic?}

As a major cause of maternal and neonatal mortality and morbidity, hypertensive disorders of pregnancy (HDP) are a global public health problem affecting maternal and children's health.

\section{What is added by this report?}

The incidence of HDP was $6.40 \%$ among 277,632 pregnant women. With the progress of pregnancy, the proportion of pregnant women with high normal blood pressure (BP) and the incidence of HDP increased gradually. The incidence of HDP increased with pregnancy age, body mass index, and BP of pregnant women during first trimester.

What are the implications for public health practice?

To reduce the incidence of HDP effectively, we should pay more attention to older women who plan to become pregnant, measures should be taken to control $\mathrm{BP}$ and weight in pre-pregnancy.

Hypertensive disorders of pregnancy (HDP) are a group of diseases associated with elevated blood pressure (BP). As a major cause of maternal and neonatal mortality and morbidity, HDP can trigger severe forms of maternal complications ( 1 ) and is a risk factor for hypertension (HTN) and other cardiovascular diseases after pregnancy (2), seriously affecting maternal and children's health. In China, most of the relevant literature has been focused on a small sample of individual hospitals or just one disease in HDP (3). This study is based on population monitoring data to obtain the BP level in pregnancy, the incidence of HDP in monitoring areas of China, and related influencing factors, so as to provide a scientific basis for the development of HDP control and prevention.

Through the Maternal and Newborn Health Monitoring System* (MNHMS), a total of 277,632 single-fetus pregnant women that delivered during 2014-2018 in 16 counties of 8 provinces were monitored. The incidence of HDP was $6.40 \%$. BP and the incidence of HDP increased with age, body mass index (BMI) and BP during the first trimester, and the gestational age. Primiparity, history of cesarean, lower education level, living in rural areas were the risk factors for HDP. Therefore, more measures should be taken to avoid advanced pregnancy and strengthen prepregnancy healthcare, so that pregnant women maintain their BP and weight within the normal range pre-pregnancy, which can reduce the occurrence of HDP effectively.

Data were obtained from the MNHMS set up by the National Center for Women and Children's Health (NCWCH) for Maternal and Newborn Health Monitoring Program ${ }^{\dagger}$ (MNHMP) in 2013. A total of 281,283 women (delivered between January 1, 2014 and December 31,2018) had at least 1 record of BP during prenatal examination. Women with 2 or multiple fetuses (3,388 persons), with only 1 record but abnormal value of BP (263 persons), were excluded. Finally, the data of 277,632 registered pregnant women were analyzed in this study.

The highest value of $\mathrm{BP}$ readings in each antenatal examination during each trimester was documented and analyzed. According to "Diagnosis and Treatment of Hypertension and Pre-eclampsia in Pregnancy: A Clinical Practice Guideline in China (2020)" (4), "Internal Medicine (Ninth Edition)," and research needs, BP was divided into 5 categories: systolic BP $(\mathrm{SBP})<90$ and/or diastolic BP (DBP) $<60$ was low; $90 \leq$

\footnotetext{
* The MNHMS was established to monitor the antenatal health care and pregnancy outcomes of pregnant women who had lived more than 6 months in the 16 districts/counties of 8 provinces. The 8 provinces (with the selected districts) are: Hebei (Xinhua and Zhengding), Liaoning (Lishan, Tiedong and Tai'an), Fujian (Haicang and Jimei), Hubei (Macheng and Luotian), Hunan (Yueyanglou and Yueyang), Guangdong (Zijin and Longchuan), Sichuan (Gongjing and Rong county), and Yunnan (Tonghai and Huaning). Among them, Macheng and Luotian in Hubei, Zijin and Longchuan in Guangdong, and Tiedong in Liaoning joined the project in 2016, and Tai' an in Liaoning withdrew in 2016.

$\dagger$ To ensure the quality of the information, the system set many logics checks to prevent wrong inputs. In addition, the staff of the NCWCH conducted field supervision on data accuracy every year. MNHMP was approved by the Ethics Committee of the NCWCH (No.FY2015-007).
} 
$\mathrm{SBP}<120$ and/or $60 \leq \mathrm{DBP}<80$ was normal; $120 \leq$ $\mathrm{SBP}<140$ and/or $80 \leq \mathrm{DBP}<90$ was high normal; $140 \leq$ $\mathrm{SBP}<160$ and/or $90 \leq \mathrm{DBP}<110$ was generally high; and $S B P \geq 160$ and/or $\mathrm{DBP} \geq 110$ was severely high. The standard for HDP was at least 1 measurement of $\mathrm{SBP} \geq$ $140 \mathrm{mmHg}$ and/or DBP $\geq 90 \mathrm{mmHg}$.

The mean age of pregnant women was $28.0 \pm 4.7$ years old. The mean number of antenatal examinations was $7.3 \pm 3.5$ times, and the mean gestational week of delivery was $39.0 \pm 1.5$ weeks. The mean max SBP during pregnancy was $120.4 \pm 11.0 \mathrm{mmHg}$, and the mean max DBP was $76.5 \pm 8.1 \mathrm{mmHg}$. The total incidence of HDP was $6.40 \%$.

The rate of detection of HDP in first, second, and third trimester of pregnancy was $0.89 \%, 1.80 \%$, and $5.62 \%$, respectively. From the first trimester to third trimester, non-HDP pregnant women had an average increase of $11.7 \mathrm{mmHg}$ in SBP and $6.8 \mathrm{mmHg}$ in DBP, while HDP pregnant women had an average increase of $20.9 \mathrm{mmHg}$ in $\mathrm{SBP}$ and $15.0 \mathrm{mmHg}$ in DBP. The proportion of the low group and the normal group of SBP and DBP decreased, while the proportions of the high normal group, the generally high group, and the severely high group increased gradually. (Table 1)

There were statistically significant differences in the levels of BP and the incidence of HDP between different provinces, ages, education levels, ethnicities, pregnancy histories, antenatal examination times, BMIs, and BPs during initial examination in first trimester and whether with gestational diabetes mellitus $(\mathrm{GDM}) \quad(P<0.05)$. The highest agestandardized incidence of HDP was in Yunnan $(8.42 \%)$, followed by in Hebei $(7.99 \%)$, Liaoning (7.95), Fujian (6.53\%), Hubei (6.27\%), Sichuan (5.20\%), and Hunan (4.39\%), and the lowest was in Guangdong (3.20\%). The age-standardized incidence of HDP in ethnic minorities $(7.43 \%)$ was higher than those with Han ethnicity (6.38\%). Pregnant women with lower education, primiparity, history of abortion or cesarean section, and GDM had higher incidence of HDP. With an increase in age, BMI, and BP in the first trimester and the number of antenatal examinations, SBP, DBP, and the incidence of HDP increased (Table 2).

The multivariable logistic regression analysis showed that living in rural areas, older age, lower education, history of cesarean section, GDM, and high BMI in first trimester were risk factors for HDP. Taking 25-29 years old as reference, odds ratio (OR) values of 35-39 years old and over 40 years old were 1.832 and 2.650, respectively. Taking normal weight in first trimester as reference, OR values of overweight and obesity were 2.145 and 4.998 , respectively (Table 3).

TABLE 1. BP levels and classification proportion in different trimesters of pregnant women -8 provinces in China, 2014-2018 (95\% Cl).

\begin{tabular}{|c|c|c|c|c|c|c|c|c|c|}
\hline \multirow{2}{*}{ Variables } & \multirow{2}{*}{$\mathbf{N}$} & \multicolumn{3}{|c|}{$\mathrm{BP}(\mathrm{mmHg})$} & \multicolumn{5}{|c|}{ Classification proportion (\%) } \\
\hline & & Total & Non HDP & HDP & Low & Normal & High normal & Generally high & Severely high \\
\hline \multicolumn{10}{|l|}{ SBP } \\
\hline First trimester & 167237 & 106.7 & 106.1 & 115.8 & 1.47 & 82.41 & 15.73 & 0.35 & 0.04 \\
\hline & 252,172 & $\begin{array}{c}(106.7-106.8) \\
112.9\end{array}$ & $\begin{array}{c}(106.0-106.2) \\
112.1\end{array}$ & $\begin{array}{c}(115.6-116.1) \\
124.6\end{array}$ & $\begin{array}{c}(1.41-1.53) \\
0.42\end{array}$ & $\begin{array}{c}(82.23-82.59) \\
67.73\end{array}$ & $\begin{array}{c}(15.56-15.90) \\
30.91\end{array}$ & $\begin{array}{c}(0.32-0.38) \\
0.86\end{array}$ & $\begin{array}{c}(0.03-0.05) \\
0.09\end{array}$ \\
\hline Third trimester & 261,106 & $\begin{array}{c}(112.9-113.0) \\
119.1 \\
(119.0-119.1)\end{array}$ & $\begin{array}{c}(112.1-112.2) \\
117.8 \\
(117.8-117.8)\end{array}$ & $\begin{array}{c}(124.4-124.8) \\
136.7 \\
(136.5-136.9)\end{array}$ & $\begin{array}{c}(0.39-0.45) \\
0.08 \\
(0.07-0.09)\end{array}$ & $\begin{array}{c}(67.55-67.91) \\
46.48 \\
(46.29-46.67)\end{array}$ & $\begin{array}{c}(30.73-31.09) \\
50.39 \\
(50.20-50.58)\end{array}$ & $\begin{array}{c}(0.82-0.90) \\
2.74 \\
(2.68-2.80)\end{array}$ & $\begin{array}{c}(0.08-0.10) \\
0.32 \\
(0.30-0.34)\end{array}$ \\
\hline$P$ value & & $<0.001^{*}$ & $<0.001^{*}$ & $<0.001^{*}$ & $<0.001^{*}$ & $<0.001^{*}$ & $<0.001^{*}$ & $<0.001^{*}$ & $<0.001^{*}$ \\
\hline \multicolumn{10}{|l|}{ DBP } \\
\hline First trimester & 167,209 & $\begin{array}{c}67.8 \\
(67.8-67.9) \\
70.7\end{array}$ & $\begin{array}{c}67.4 \\
(67.3-67.4) \\
70.1\end{array}$ & $\begin{array}{c}75.0 \\
(74.8-75.2) \\
80.0\end{array}$ & $\begin{array}{c}5.44 \\
(5.33-5.55) \\
3.77\end{array}$ & $\begin{array}{c}83.18 \\
(83.00-83.36) \\
77.91\end{array}$ & $\begin{array}{c}10.64 \\
(10.49-10.79) \\
16.98\end{array}$ & $\begin{array}{c}0.71 \\
(0.67-0.75) \\
1.30\end{array}$ & $\begin{array}{c}0.03 \\
(0.02-0.04) \\
0.04\end{array}$ \\
\hline Third trimester & 261,109 & $\begin{array}{c}(70.7-70.7) \\
75.3 \\
(75.3-75.3)\end{array}$ & $\begin{array}{c}(70.0-70.1) \\
74.2 \\
(74.2-74.3)\end{array}$ & $\begin{array}{c}(79.8-80.2) \\
90.0 \\
(89.9-90.1)\end{array}$ & $\begin{array}{c}(3.70-3.84) \\
1.31 \\
(1.27-1.35)\end{array}$ & $\begin{array}{c}(77.75-78.07) \\
62.46 \\
(62.27-62.65)\end{array}$ & $\begin{array}{c}(16.83-17.13) \\
31.81 \\
(31.63-31.99)\end{array}$ & $\begin{array}{c}(1.26-1.34) \\
4.22 \\
(4.14-4.30)\end{array}$ & $\begin{array}{c}(0.03-0.05) \\
0.20 \\
(0.18-0.22)\end{array}$ \\
\hline$P$ value & & $<0.001^{*}$ & $<0.001^{\star}$ & $<0.001^{*}$ & $<0.001^{*}$ & $<0.001^{*}$ & $<0.001^{*}$ & $<0.001^{*}$ & $<0.001^{*}$ \\
\hline
\end{tabular}

Note: Related definitions: first trimester is from the beginning of pregnancy to the end of the 12th week, second trimester is from the 13th week of pregnancy to the end of the 27th week, and third trimester is from the 28th week of pregnancy to the end of childbirth.

Classification of SBP: SBP $<90$ is low, $90 \leq \mathrm{SBP}<120$ is normal, $120 \leq \mathrm{SBP}<140$ is high normal, $140 \leq \mathrm{SBP}<160$ is generally high, $\mathrm{SBP} \geq 160$ is severely high.

Classification of DBP: $D B P<60$ is low, $60 \leq D B P<80$ is normal, $80 \leq D B P<90$ is high normal, $90 \leq \mathrm{DBP}<110$ is generally high, $\mathrm{DBP} \geq 110$ is severely high. Abbreviations: $\mathrm{BP}=$ blood pressure, $\mathrm{SBP}=$ systolic blood pressure, $\mathrm{DBP}=$ diastolic blood pressure,

* the $P$ value of linear trend test. 
TABLE 2. BP levels and incidence of HDP among different factors of pregnant womenin 8 provinces in China, 2014-2018 $(95 \% \mathrm{Cl})$.

\begin{tabular}{|c|c|c|c|c|c|}
\hline \multirow{2}{*}{ Variables } & \multirow[b]{2}{*}{$\mathbf{N}$} & \multirow{2}{*}{ SBP $(\mathrm{mmHg})$} & \multirow{2}{*}{ DBP (mmHg) } & \multicolumn{2}{|c|}{ Incidence of HDP (\%) } \\
\hline & & & & Roughness & Age-standardized \\
\hline \multicolumn{6}{|l|}{ Province } \\
\hline Hebei & 61,270 & $120.0(119.9-120.0)$ & $76.8(76.8-76.9)$ & 7.95(7.74-8.16) & $7.99(7.78-8.20)$ \\
\hline Liaoning & 18,482 & 119.0(118.9-119.2) & 77.1(77.0-77.2) & $8.32(7.92-8.72)$ & $7.95(7.56-8.34)$ \\
\hline Fujian & 56,672 & $124.4(124.3-124.5)$ & 76.3(76.2-76.3) & $6.53(6.33-6.73)$ & $6.53(6.32-6.74)$ \\
\hline Hubei & 32,058 & 115.6(115.4-115.7) & $75.1(75.0-75.2)$ & $6.17(5.91-6.43)$ & $6.27(6.00-6.54)$ \\
\hline Hunan & 40,122 & $120.1(120.0-120.2)$ & $75.9(75.8-75.9)$ & $4.47(4.27-4.67)$ & $4.39(4.19-4.59)$ \\
\hline Guangdong & 21,771 & 121.2(121.0-121.3) & 74.6(74.5-74.7) & $3.27(3.03-3.51)$ & $3.20(2.97-3.43)$ \\
\hline Sichuan & 21,835 & 119.2(119.0-119.3) & $76.9(76.8-77.0)$ & $5.13(4.84-5.42)$ & $5.20(4.90-5.50)$ \\
\hline Yunnan & 25,422 & $120.5(120.3-120.6)$ & 79.7(79.6-79.8) & $8.05(7.72-8.38)$ & $8.42(8.08-8.76)$ \\
\hline$P$ value & & $<0.001$ & $<0.001$ & & $<0.001$ \\
\hline \multicolumn{6}{|l|}{ Area type } \\
\hline Urban & 136,832 & 121.5(121.5-121.6) & $76.4(76.3-76.4)$ & $6.52(6.39-6.65)$ & $6.42(6.29-6.55)$ \\
\hline Rural & 140,800 & 119.3(119.2-119.3) & 76.6(76.5-76.6) & $6.28(6.15-6.41)$ & $6.38(6.25-6.51)$ \\
\hline$P$ value & & $<0.001$ & $<0.001$ & & 0.675 \\
\hline \multicolumn{6}{|l|}{ Age of pregnancy $(y)$} \\
\hline$\leq 19$ & 5,598 & 118.7(118.4-119.0) & $75.6(75.4-75.8)$ & $4.50(3.96-5.04)$ & - \\
\hline $20-24$ & 56,228 & 119.8(119.7-119.9) & $76.3(76.2-76.3)$ & $5.45(5.26-5.64)$ & - \\
\hline $25-29$ & 124,225 & $120.1(120.0-120.1)$ & 76.3(76.3-76.4) & $5.87(5.74-6.00)$ & - \\
\hline $30-34$ & 63,191 & $120.9(120.8-121.0)$ & $76.6(76.6-76.7)$ & $6.93(6.73-7.13)$ & - \\
\hline $35-39$ & 22,649 & $122.0(121.8-122.1)$ & 77.3(77.2-77.4) & $9.29(8.91-9.67)$ & - \\
\hline$\geq 40$ & 4,417 & $123.8(123.4-124.2)$ & 78.5(78.3-78.8) & $13.06(12.07-14.05)$ & - \\
\hline$P$ value & & $<0.001^{*}$ & $<0.001^{*}$ & $<0.001^{*}$ & - \\
\hline \multicolumn{6}{|l|}{ Education level } \\
\hline Junior high school or lower & 94,482 & $120.5(120.4-120.5)$ & $76.8(76.7-76.8)$ & $6.83(6.67-6.99)$ & $6.83(6.67-6.99)$ \\
\hline Senior high & 79,642 & 119.7(119.6-119.7) & $76.4(76.3-76.4)$ & $6.20(6.03-6.37)$ & $6.30(6.13-6.47)$ \\
\hline University or above & 89,357 & 121.1(121.0-121.2) & $76.4(76.3-76.4)$ & $6.05(5.89-6.21)$ & $5.96(5.80-6.12)$ \\
\hline$P$ value & & $<0.001$ & $<0.001$ & & $<0.001^{*}$ \\
\hline \multicolumn{6}{|l|}{ Ethnicity } \\
\hline Han & 260,306 & 120.3(120.3-120.4) & $76.5(76.4-76.5)$ & $6.39(6.30-6.48)$ & $6.38(6.29-6.47)$ \\
\hline Others & 8,011 & 119.7(119.5-119.9) & $78.2(78.0-78.3)$ & $7.05(6.49-7.61)$ & $7.43(6.85-8.01)$ \\
\hline$P$ value & & $<0.001$ & $<0.001$ & & $<0.001$ \\
\hline \multicolumn{6}{|l|}{ Parity } \\
\hline 0 & 148,878 & $120.1(120.0-120.1)$ & $76.6(76.6-76.7)$ & $6.60(6.47-6.73)$ & $7.05(6.92-7.18)$ \\
\hline$\geq 1$ & 120,059 & $120.9(120.9-121.0)$ & $76.4(76.4-76.4)$ & $6.37(6.23-6.51)$ & $5.81(5.68-5.94)$ \\
\hline$P$ value & & $<0.001$ & $<0.001$ & & $<0.001$ \\
\hline \multicolumn{6}{|l|}{ History of cesarean section } \\
\hline No & 223,153 & $120.3(120.3-120.3)$ & 76.4(76.4-76.5) & $6.27(6.17-6.37)$ & $6.37(6.27-6.47)$ \\
\hline Yes & 45,787 & 121.2(121.1-121.3) & $76.9(76.9-77.0)$ & 7.57(7.33-7.81) & $6.96(6.73-7.19)$ \\
\hline$P$ value & & $<0.001$ & $<0.001$ & & $<0.001$ \\
\hline
\end{tabular}


TABLE 2. (Continued)

\begin{tabular}{|c|c|c|c|c|c|}
\hline \multirow{2}{*}{ Variables } & \multirow{2}{*}{$\mathbf{N}$} & \multirow{2}{*}{ SBP $(\mathrm{mmHg})$} & \multirow{2}{*}{ DBP (mmHg) } & \multicolumn{2}{|c|}{ Incidence of HDP (\%) } \\
\hline & & & & Roughness & Age-standardized \\
\hline \multicolumn{6}{|l|}{ History of abortion } \\
\hline No & 136,853 & $121.0(120.9-121.0)$ & 76.7(76.7-76.7) & $6.36(6.23-6.49)$ & $6.53(6.40-6.66)$ \\
\hline Yes & 79,257 & $120.8(120.7-120.9)$ & $77.0(77.0-77.1)$ & 7.12(6.94-7.30) & $6.75(6.57-6.93)$ \\
\hline$P$ value & & $<0.001$ & $<0.001$ & & 0.049 \\
\hline \multicolumn{6}{|l|}{ GDM } \\
\hline No & 128,533 & 121.3(121.3-121.4) & 76.6(76.5-76.6) & $6.29(6.16-6.42)$ & $6.18(6.05-6.31)$ \\
\hline Yes & 6,930 & 126.1(125.9-126.4) & 78.4(78.2-78.6) & $10.29(9.57-11.01)$ & $9.73(9.03-10.43)$ \\
\hline Unchecked & 142,169 & 119.3(119.2-119.3) & 76.3(76.3-76.4) & $6.30(6.17-6.43)$ & $6.46(6.33-6.59)$ \\
\hline$P$ value & & $<0.001$ & $<0.001$ & & $<0.001$ \\
\hline \multicolumn{6}{|c|}{$\mathrm{BMI}$ in first trimester $\left(\mathrm{kg} / \mathrm{m}^{2}\right)$} \\
\hline Lean & 25,772 & 118.4(118.3-118.6) & 75.3(75.2-75.4) & $3.29(3.07-3.51)$ & $3.36(3.14-3.58)$ \\
\hline Normal & 108,384 & $120.1(120.1-120.2)$ & 76.3(76.3-76.4) & $4.87(4.74-5.00)$ & $4.87(4.74-5.00)$ \\
\hline Overweight & 24,151 & $124.0(123.8-124.1)$ & 79.4(79.3-79.5) & $10.89(10.50-11.28)$ & $10.61(10.22-11.00)$ \\
\hline Obesity & 7,096 & $127.8(127.5-128.0)$ & 82.9(82.7-83.1) & $22.82(21.84-23.80)$ & $22.45(21.48-23.42)$ \\
\hline Unchecked & 112,229 & 119.9(119.8-119.9) & 75.9(75.8-75.9) & $6.57(6.43-6.71)$ & $6.57(6.42-6.72)$ \\
\hline$P$ value & & $<0.001^{*}$ & $<0.001^{*}$ & & $<0.001^{*}$ \\
\hline \multicolumn{6}{|l|}{ BP in first trimester } \\
\hline Low & 11,056 & 116.8(116.6-117.0) & $72.0(71.8-72.1)$ & $2.17(1.90-2.44)$ & $2.17(1.90-2.44)$ \\
\hline Normal & 124,036 & 119.2(119.2-119.3) & $76.0(75.9-76.0)$ & $4.10(3.99-4.21)$ & $4.12(4.01-4.23)$ \\
\hline High normal & 29,850 & $127.6(127.5-127.7)$ & 81.8(81.8-81.9) & $12.77(12.39-13.15)$ & $12.58(12.20-12.96)$ \\
\hline High & 1,308 & $141.3(140.5-142.1)$ & $94.9(94.4-95.4)$ & 100 & 100 \\
\hline Unchecked & 111,382 & 119.9(119.8-120.0) & $75.9(75.8-75.9)$ & $6.56(6.41-6.71)$ & $6.55(6.40-6.70)$ \\
\hline$P$ value & & $<0.001^{*}$ & $<0.001^{*}$ & & $<0.001^{*}$ \\
\hline \multicolumn{6}{|c|}{ Number of antenatal examinations } \\
\hline $1-3$ & 36,067 & 114.0(113.9-114.1) & 71.7(71.6-71.7) & $3.30(3.12-3.48)$ & $3.27(3.09-3.45)$ \\
\hline $4-6$ & 91,579 & 118.8(118.8-118.9) & $75.8(75.7-75.8)$ & $5.12(4.98-5.26)$ & $5.12(4.98-5.26)$ \\
\hline $7-9$ & 73,980 & $122.0(121.9-122.0)$ & 77.5(77.5-77.6) & 7.60(7.41-7.79) & 7.54(7.35-7.73) \\
\hline$\geq 10$ & 76,006 & 123.8(123.7-123.9) & 78.7(78.6-78.7) & $8.23(8.03-8.43)$ & $8.30(8.10-8.50)$ \\
\hline$P$ value & & $<0.001^{*}$ & $<0.001^{*}$ & & $<0.001^{*}$ \\
\hline
\end{tabular}

Note: first trimester is from the beginning of pregnancy to the end of the 12th week; "-" means the variable needn't to be age-standardized. Classification of BMI: $18.5 \leq \mathrm{BMl}<24 \mathrm{~kg} / \mathrm{m}^{2}$ is normal, $\mathrm{BMl}<18.5 \mathrm{~kg} / \mathrm{m}^{2}$ is lean, $24 \leq \mathrm{BMl}<28 \mathrm{~kg} / \mathrm{m}^{2}$ is overweight, $\mathrm{BMl} \geq 28 \mathrm{~kg} / \mathrm{m}^{2}$ is obesity. Abbreviations: $\mathrm{BP}=$ blood pressure, $\mathrm{HDP}=$ hypertensive disorders of pregnancy, $\mathrm{SBP}=$ systolic blood pressure, $\mathrm{DBP}=$ diastolic blood pressure, $\mathrm{GDM}=$ gestational diabetes mellitus, BMI=body mass index.

* the $P$ value of linear trend test.

TABLE 3. Multivariate logistic regression model for HDP - 8 provinces in China, 2014-2018.

\begin{tabular}{|c|c|c|c|c|c|c|}
\hline Variables & $\beta$ & S.E. & Wald $x^{2}$ & $P$ value & OR & $95 \% \mathrm{Cl}$ \\
\hline \multicolumn{7}{|l|}{ Province } \\
\hline Hunan & & & & & Ref & \\
\hline Hebei & 0.356 & 0.035 & 105.215 & $<0.001$ & 1.428 & $1.334-1.528$ \\
\hline Liaoning & 0.181 & 0.043 & 17.820 & $<0.001$ & 1.198 & $1.102-1.303$ \\
\hline Fujian & 0.153 & 0.039 & 15.633 & $<0.001$ & 1.166 & $1.080-1.257$ \\
\hline Hubei & 0.271 & 0.042 & 41.107 & $<0.001$ & 1.311 & $1.207-1.424$ \\
\hline Guangdong & -0.405 & 0.051 & 64.011 & $<0.001$ & 0.667 & $0.604-0.737$ \\
\hline
\end{tabular}


TABLE 3. (Continued)

\begin{tabular}{|c|c|c|c|c|c|c|}
\hline Variables & $\beta$ & S.E. & Wald $x^{2}$ & $P$ value & OR & $95 \% \mathrm{Cl}$ \\
\hline Sichuan & -0.224 & 0.044 & 25.727 & $<0.001$ & 0.799 & $0.733-0.872$ \\
\hline Yunnan & -0.002 & 0.041 & 0.003 & 0.953 & 0.998 & 0.920-1.082 \\
\hline \multicolumn{7}{|l|}{ Areas } \\
\hline Urban & & & & & Ref & \\
\hline Rural & 0.220 & 0.023 & 88.876 & $<0.001$ & 1.246 & $1.190-1.304$ \\
\hline \multicolumn{7}{|l|}{ Age of pregnancy $(y)$} \\
\hline$\leq 19$ & -0.392 & 0.071 & 30.714 & $<0.001$ & 0.676 & $0.588-0.776$ \\
\hline $20-24$ & -0.136 & 0.024 & 31.356 & $<0.001$ & 0.873 & $0.833-0.916$ \\
\hline $25-29$ & & & & & Ref & \\
\hline $30-34$ & 0.226 & 0.022 & 110.058 & $<0.001$ & 1.253 & $1.202-1.307$ \\
\hline $35-39$ & 0.606 & 0.028 & 455.792 & $<0.001$ & 1.832 & $1.733-1.937$ \\
\hline$\geq 40$ & 0.975 & 0.050 & 373.888 & $<0.001$ & 2.650 & $2.401-2.925$ \\
\hline \multicolumn{7}{|l|}{ Education } \\
\hline Junior high school or lower & 0.135 & 0.021 & 41.739 & $<0.001$ & 1.144 & $1.098-1.192$ \\
\hline Senior high & & & & & Ref & \\
\hline University or above & -0.237 & 0.023 & 109.753 & $<0.001$ & 0.789 & $0.755-0.825$ \\
\hline \multicolumn{7}{|l|}{ Parity } \\
\hline 0 & & & & & Ref & \\
\hline$\geq 1$ & -0.432 & 0.023 & 350.459 & $<0.001$ & 0.649 & $0.620-0.679$ \\
\hline \multicolumn{7}{|l|}{ History of cesarean section } \\
\hline No & & & & & Ref & \\
\hline Yes & 0.130 & 0.025 & 26.108 & $<0.001$ & 1.139 & $1.083-1.197$ \\
\hline \multicolumn{7}{|l|}{ GDM } \\
\hline No & & & & & Ref & \\
\hline Yes & 0.307 & 0.044 & 48.353 & $<0.001$ & 1.359 & $1.247-1.482$ \\
\hline Unchecked & -0.026 & 0.018 & 2.006 & 0.157 & 0.974 & $0.939-1.010$ \\
\hline \multicolumn{7}{|l|}{ BMI in first trimester $\left(\mathrm{kg} / \mathrm{m}^{2}\right)$} \\
\hline Lean & -0.365 & 0.039 & 85.992 & $<0.001$ & 0.694 & $0.643-0.750$ \\
\hline Normal & & & & & Ref & \\
\hline Overweight & 0.763 & 0.026 & 838.535 & $<0.001$ & 2.145 & $2.037-2.258$ \\
\hline Obesity & 1.609 & 0.034 & 2285.146 & $<0.001$ & 4.998 & $4.679-5.339$ \\
\hline Unchecked & 0.451 & 0.021 & 459.159 & $<0.001$ & 1.571 & $1.507-1.637$ \\
\hline \multicolumn{7}{|c|}{ Number of antenatal examinations } \\
\hline $1-3$ & -0.569 & 0.035 & 261.247 & $<0.001$ & 0.566 & $0.528-0.606$ \\
\hline $4-6$ & & & & & Ref & \\
\hline $7-9$ & 0.382 & 0.023 & 278.406 & $<0.001$ & 1.465 & $1.401-1.533$ \\
\hline$\geq 10$ & 0.621 & 0.026 & 589.2 & $<0.001$ & 1.861 & $1.770-1.957$ \\
\hline
\end{tabular}

Note: first trimester is from the beginning of pregnancy to the end of the 12th week.

Classification of BMI: $18.5 \leq \mathrm{BMl}<24 \mathrm{~kg} / \mathrm{m}^{2}$ is normal, $\mathrm{BMl}<18.5 \mathrm{~kg} / \mathrm{m}^{2}$ is lean, $24 \leq \mathrm{BMl}<28 \mathrm{~kg} / \mathrm{m}^{2}$ is overweight, $\mathrm{BMl} \geq 28 \mathrm{~kg} / \mathrm{m}^{2}$ is obesity.

Abbreviations: $\mathrm{BP}=$ blood pressure, $\mathrm{HDP}=$ hypertensive disorders of pregnancy, $\mathrm{GDM}=$ gestational diabetes mellitus, $\mathrm{BMI}=$ body mass index, $\beta=$ regression coefficient, S.E.=standard error, OR=odds ratio, $\mathrm{Cl}=$ confidence interval.

\section{DISCUSSION}

The increase of $\mathrm{BP}$ in normal ranges during pregnancy may be an adaptive physiological response. However, excess increase in BP would lead to HDP and endanger maternal and infant health. This study 
showed that with the progress of pregnancy, SBP and DBP increased gradually in HDP pregnant women or non-HDP pregnant women, and the proportion of pregnant women with high normal $\mathrm{BP}$ and the incidence of HDP were also increased, which is consistent with a previous study (5). However, some studies believed that BP was lowest in the second trimester, then rose in the third trimester (6-7). A study by Wang et al. (8) showed that the SBP/DBP of $18-24$ and $25-34$-year-old was $117.4 / 71.4 \mathrm{mmHg}$ and $118.9 / 73.2 \mathrm{mmHg}$, respectively, and the corresponding prevalence of HTN was $4.0 \%$ and $6.1 \%$, respectively. In this study, the SBP/DBP of pregnant women under 24 years old and 25-34 years old was $119.7 / 76.2 \mathrm{mmHg}$ and $120.3 / 76.4 \mathrm{mmHg}$, respectively, and the incidence of HDP was $5.45 \%$ and $6.23 \%$, respectively, which were higher than the $\mathrm{BP}$ level and the prevalence of HTN in the total women population of the same age group in the above study. Therefore, we should pay more attention to control BP when women become pregnant.

Many studies have shown that the incidence of HDP in different countries was 5\%-10\% (1,9-10). The incidence of HDP was $6.40 \%$ in this study. This is consistent with a cross-sectional survey conducted by Ye et al. in 2011 based on about 110,000 Chinese people, in which the prevalence of HDP in China was $5.22 \%$ (3). In this study, the age-standardized incidence of HDP was highest in Yunnan, followed by Hebei, Liaoning, Fujian, Hubei, and Sichuan, and lowest in Hunan and Guangdong, part of which were consistent with the Ye et al. study on HDP (3) and the Wang et al. study on HTN (8). This indicated that regional differences were important factors affecting HDP.

This study concluded that the incidence of HDP increased with age, BP, and BMI in the first trimester. The age-standardized incidence of HDP with high normal BP in the first trimester $(12.58 \%)$ was about 3 times higher than that with normal BP (4.12\%). Compared with pregnant women aged 25-29 years old, the risk of HDP was nearly doubled over 35 years old $(\mathrm{OR}=1.832)$ and increased up to 2.7 times over 40 years old $(\mathrm{OR}=2.650)$. Taking pregnant women with normal weight in first trimester as reference, pregnant women with overweight had a doubled risk for HDP $(\mathrm{OR}=2.145)$ and with obesity increased the risk up to 5 times $(\mathrm{OR}=4.998)$, which were similar to the results of several related studies $(3,8,10)$. Another important finding of this study was that, although the incidence of HDP in urban areas had no difference with that in rural areas, rural areas became a risk factor in multivariable analysis. Lower education was a risk factor for HDP, which was similar to some of the results of related studies $(3,8)$. This may be related to pregnant women living in rural areas or with lower education having lower levels of pregnancy health knowledge and more unhealthy behavior.

In conclusion, although BP during pregnancy increases are expected, important risk factors for the occurrence of HDP include area types (rural or urban residence), maternal age, early pregnancy weight, and BP. Therefore, we should pay more attention to highrisk groups, especially to older women who plan to become pregnant, and strengthen pre-pregnancy healthcare so that more pregnant women can maintain their BP and weight within normal ranges before pregnancy, thereby reducing the occurrence of HDP effectively.

One of the strengths of this study is using the BP data from individual clinical data of pregnant women in all midwifery institutions in the monitoring areas during 2014-2018, thereby reducing the time bias and institution selection bias. However, this study was subject to some limitations. First, the monitoring area was limited to 16 counties/districts in 8 provinces, so the results might not be representative of the regional and national levels. Second, due to the limited data, BP and weight before pregnancy, history of HTN, smoking and drinking, family history, and other pregnancy complications with a high rate of being missing from the data were not included as influencing factors, so it was impossible to further analyze the incidence of each group of HDP diseases.

Acknowledgments: All staff in data collection, data entry and reporting in the monitoring areas (including Xinhua, Zhengding, Lishan, Tiedong, Tai'an, Haicang, Jimei, Macheng, Luotian, Yueyanglou, Yueyang County, Zijin, Longchuan, Gongjing, Rong County, Tonghai, and Huaning); the managers of MNHMP in the above monitoring areas.

doi: $10.46234 / \mathrm{ccdcw} 2021.122$

\# Corresponding author: Jiangli Di, dijiangli@chinawch.org.cn.

${ }^{1}$ National Center for Women and Children's Health, Chinese Center for Disease Control and Prevention, Beijing, China.

Submitted: April 01, 2021; Accepted: May 25, 2021

\section{REFERENCES}

1. Ahmad AS, Samuelsen SO. Hypertensive disorders in pregnancy and fetal death at different gestational lengths: a population study of 2121 
371 pregnancies. BJOG 2012;119(12):1521 - 8. http://dx.doi.org/10 1111/j.1471-0528.2012.03460.x.

2. Benschop L, Duvekot JJ, van Lennep JER. Future risk of cardiovascular disease risk factors and events in women after a hypertensive disorder of pregnancy. Heart 2019;105(16):1273 - 8. http://dx.doi.org/10.1136/ heartjnl-2018-313453.

3. Ye C, Ruan Y, Zou LY, Li GH, Li CD, Chen Y, et al. The 2011 survey on hypertensive disorders of pregnancy (HDP) in China: prevalence, risk factors, complications, pregnancy and perinatal outcomes. PLoS One 2014;9(6):e100180. http://dx.doi.org/10.1371/journal.pone.01 00180.

4. Hypertensive Disorders in Pregnancy Subgroup, Chinese Society of Obstetrics and Gynecology, Chinese Medical Association. Diagnosis and treatment of hypertension and pre-eclampsia in pregnancy: a clinical practice guideline in China (2020). Chin J Obstet Gynecol 2020;55(4):227 - 38. http://dx.doi.org/10.3760/cma.j.cn112141-202 00114-00039. (In Chinese).

5. Wang SY, Zhou SJ, Wen SW, Tan HZ, Luo ML, Guo YW, et al. Changes in blood pressure and related determinants before and during normal pregnancy. Chin J Epidemiol 2013;34(3):241 - 4. http://dx. doi.org/10.3760/cma.j.issn.0254-6450.2013.03.009. (In Chinese).

6. Ye YH, Chen SM, Che YC, Liu PQ. The study of blood pressure changing patterns in normal pregnancy and pregnancy-induced hypertension. Chin J Perinat Med 2000;3(4):208 - 10. http://dx. doi.org/10.3760/cma.j.issn.1007-9408.2000.04.005. (In Chinese).

7. Grindheim G, Estensen ME, Langesaeter E, Rosseland LA, Toska K. Changes in blood pressure during healthy pregnancy: a longitudinal cohort study. J Hypertens 2012;30(2):342 - 50. http://dx.doi.org/10. 1097/HJH.0b013e32834f0b1c.

8. Wang ZW, Chen Z, Zhang LF, Wang X, Hao G, Zhang ZG, et al. Status of hypertension in China: results from the China hypertension survey, 2012-2015. Circulation 2018;137(22):2344 - 56. http://dx. doi.org/10.1161/CIRCULATIONAHA.117.032380.

9. Ghulmiyyah L, Sibai B. Maternal mortality from preeclampsia/ eclampsia. Semin Perinatol 2012;36(1):56 - 9. http://dx.doi.org/10. 1053/j.semperi.2011.09.011.

10. Umesawa M, Kobashi G. Epidemiology of hypertensive disorders in pregnancy: prevalence, risk factors, predictors and prognosis. Hypertens Res 2017;40(3):213 - 20. http://dx.doi.org/10.1038/hr.2016.126. 